\title{
Analysis and Design on University Knowledge Management Service JingQi Li ${ }^{*}$, YiJie Bian, MeiHua Qiao \\ Business School, Hohai University, China \\ *Corresponding author: Jingqi Li, PhD, lijingqi@hhu.edu.cn
}

\begin{abstract}
Service computing is a new discipline across information technology and business management. It is the solution to apply the Service Oriented Architecture (SOA) technology in eliminating gap between business services and information technology support. This paper firstly analyses the concept of University Knowledge Management Service and the background, and then designs the University Knowledge Management Service model and Knowledge Presentation Service model. Finally, the application prospect is discussed.
\end{abstract}

Key words: digital campus; service computing; knowledge management; university knowledge management service; knowledge presentation service

\section{Introduction}

\subsection{Concept of service}

OASIS $^{1}$ defined a service as a mechanism, in accordance with the provisions of the service description of the interface and consistency restriction and policy, to ensure that one or more of the ability. Eric Newcomer and Greg Lomow ${ }^{2}$ think the definition of service in the "Web Services SOA": from the business point of view, service is an IT asset, it corresponds to real world business activities or identifiable business functions, in accordance with the service policy, service can be accessed. From a technical point of view, the service is coarse grain, reusable IT assets, have well-defined interfaces, clearly make a distinction between service external interface and service implementation.

\subsection{Service classification}

Service can be divided into basic service, combined service and process service. The basic service provides basic business function. The basic service can be divided into basic data service and basic logical service. Basic data service is to read data from a back-end system, or to write data. The basic logic service is represented the basic business rules, these services are usually deal with some input data, and then returned to the corresponding results. Combined services represent a class of services, combined by other services (including basic and other combined services). A combined service embodies a "micro flow", namely short-term operation activity flow in the internal business process. Process service represents the longterm workflow or business process. From the business view, the business process service can be interrupted long-term activities flow.

\subsection{Concept of university knowledge management service}

Generally, knowledge management can be defined as creation, storage, transfer and application of knowledge, to improve the competitiveness of an organization. Knowledge management service is combined with a series of business functions and processes. It is a service process and a series of activities for the management of organizational knowledge. 
UKMS (University Knowledge Management Service) is referred to the management process of creation, storage, transfer and application of the explicit knowledge and tacit knowledge with application of knowledge management in universities. UKMS is a series of business process based on the above process knowledge management, including knowledge creation service and knowledge transfer service, knowledge storage service and knowledge application service.

\section{Backgrounds of UKMS}

\subsection{Digital campus provide the basis of data and information for UKMS}

With the advance of digital campus, university accumulates billions of data. How to use these data to promote the application of knowledge management in universities becomes a main problem for IT administrators. The data includes the basic information of students, such as learning information, consumption information, and activities information. It also includes teaching and researching information of teachers, such as teaching information and research information. It also includes management information, such as asset management, human resource management, and finance management. At the same time, along with the application of smartphone, more and more internet behaviors of campus network users can be automatically collected. These data provide data basis for knowledge management. We can mine these data to obtain useful knowledge. On the other hand, many MISs are established to meet the needs of ordinary management, which form the information system basis for knowledge management. Knowledge management is more and more embodied in its ability to knowledge accumulation and information integration.

\subsection{Knowledge management theory provides a theoretical basis for UKMS}

The theory of KM (Knowledge Management) plays a significant role in the enterprise, and has a lot of good knowledge management cases, but for universities, KM not only needs to solve the complicated problems of university organization, but also faces a lot of uncertainty. The key for KM to be achieved success in Chinese universities depends on whether the knowledge development and organizational learning across such barriers: the rigid system, inflexible management, lack of investment, lack of shared cultural, lack of mutual trust. Knowledge Management of University's goal is to achieve knowledge sharing, and promote the knowledge innovation, and ultimately come into being university core competitiveness and sustainable competitive advantage from strategy. To realize the knowledge sharing has to rely on technology, system guarantee and cultural atmosphere.

\section{UKMS solutions}

\subsection{UKMS model}

UKMS constructs the service functions based on knowledge base and knowledge base management system. Knowledge database is a database system for storing knowledge, and knowledge base management system is the information system for processing knowledge, to provide knowledge acquisition, knowledge check and knowledge presentation service.

UKMS can acquire external information and internal information. External information can be processed by knowledge acquisition service and knowledge check service, and then stored in knowledge base. Internal information can be processed by information integration 
service and data integration service, and then turned into the necessary knowledge according to the knowledge model. It will finally be stored in knowledge base. In the end, presentation service shows that knowledge in the best way to users. Figure 1 is the graph of UKMS model.

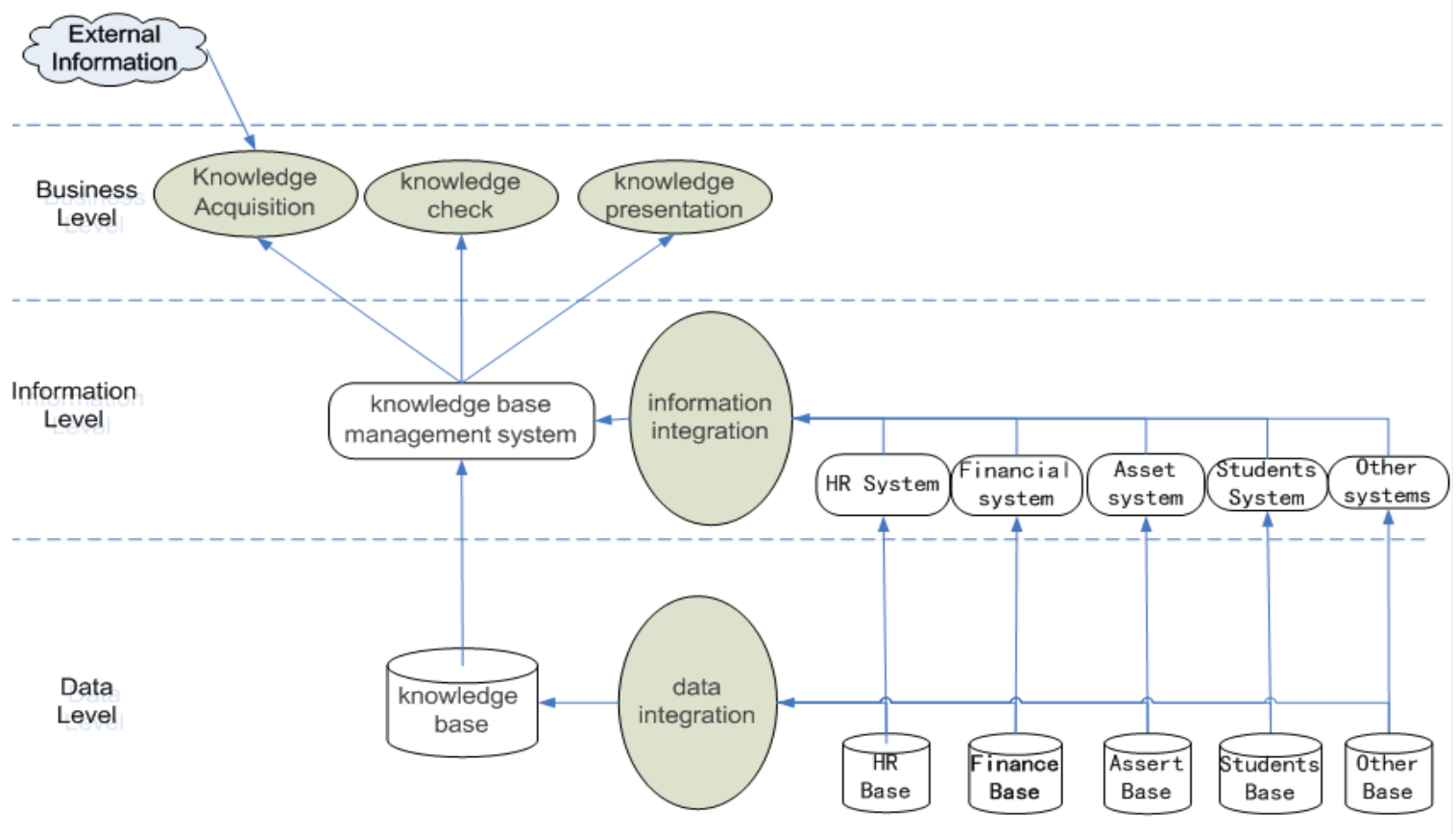

Fig. 1 - UKMS model

UKMS model can be subdivided into knowledge acquisition, knowledge check, knowledge presentation, information integration and data integration. Such five services have different functions and complete knowledge discovery process.

Knowledge acquisition service: The service acquires from the external information, and then turns information into knowledge, which will be stored in the knowledge base.

Knowledge check service: With this service, knowledge collected from external can be checked and divided into corresponding category. So users could search quickly for the knowledge which they want.

Knowledge presentation service: According to user's characteristics, such service extracts the relevant content from knowledge base, and shows it to the right user in the right way.

Information integration service: Users need to sign a large number of information systems to query information because of the isolated information systems in university. So information integration service will makes users see all the relevant information in one interface. Users can make decisions and judgments according to this information.

Data integration service: Knowledge management service is aimed to support decision making, and decision support needs a large amount of data to analyse. So data integration is particularly important.

Knowledge acquisition service is the entrance for external information, and knowledge check service is the external information gate-keeper. The two together constitute the external knowledge channel of knowledge management service. Knowledge presentation service is the most important service, is the core content of the knowledge management service. Its core technology is the construction and display of knowledge. Information integrated service is an external service. It increases integrated information content according to the need, so that the 
system can provide better experiences, make users fully understand the related information in single user interface. Data integration is the advanced stage of knowledge management service.

\subsection{Knowledge presentation service model}

Knowledge presentation service is the key service of UKMS. It includes document management, statistical information, behaviour analysis, communication management.

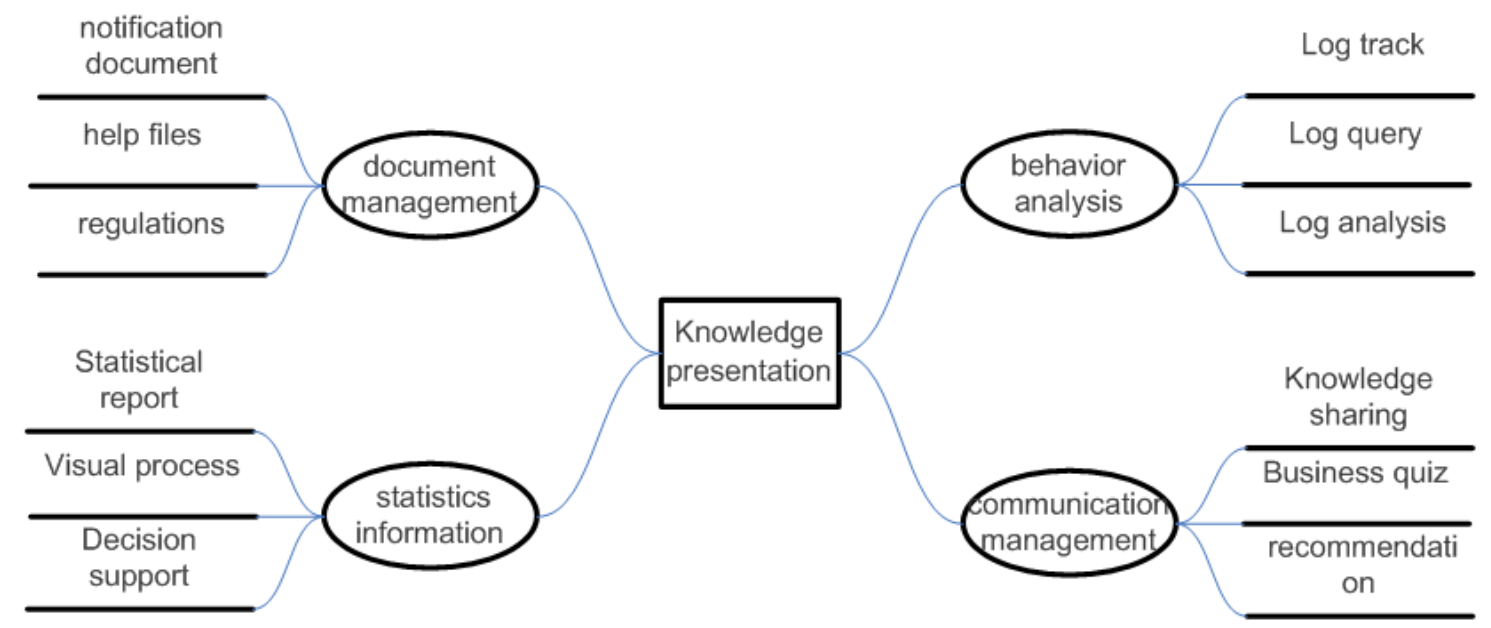

Fig. 2 -Knowledge presentation service model

Document knowledge: It is used for management of notification document, regulations and help files, which are formatted in work. Such files can be classified to explicit knowledge. Users can get business process information of a system through such documents. Statistics information: It makes managers easily obtain statistics information, and understand the working state, so as to make scientific and effective decision. The development of decision support technology provides more intelligent decision-making methods for the managers, such as the visualization of the working process, displayed in more vivid, easy to understand forms. With the support of model base, UKMS can automatically provide solutions, scientific and solid evidences.

Behavior analysis: By monitoring the log, UKMS can find a greater log value. Log track provides the tool to monitor abnormal users, to detect anomalies. Log query provide a tool for managers and users to understand themselves and others by network activity recording, so as to enhance the network of their own behavior, and improve their information capacity. Log analysis can provide managers the information for users' activities when they sign on the MISs, so as to improve the business process.

Communication management: With the view of knowledge management theory, communication is a process of externalization of tacit knowledge. Personal knowledge becomes public knowledge, and will be shared by all users. Knowledge sharing is to promote the capacity of turning individual knowledge into public knowledge. Business quiz is conducive to communicate between managers and users. It is intended to help users understand business process, so as to adjust their behaviours to suit for management. On the other hand, it makes managers to understand the users' needs and problems, so they can improve efficiency. Recommendation accumulates business questions and sharing knowledge 
which are classified separately. It will be help for users to learn business knowledge better from existing experience and improve business skills.

UKMS can provide uniform service of knowledge management for business system with information integration and data integration interface. Business system only needs to consider business processes, without considering the generation, storage, and presentation of knowledge. The goal of knowledge management service is, according to the need of business, to create knowledge management space for their business systems, and provide the knowledge presentation service.

\section{Application prospects for UKMS}

\subsection{University decision support}

University decision support is help for university managers and participants, in a timely manner, to make more scientific, timely, optimization decision based on data, information and knowledge. With knowledge management services, IT department can establish the realtime, fast decision support system, to provide decision support for managers. Teachers and students can also quickly obtain information of all aspects of individuals on learning, living situation with statistics information, so that they can make quick and suitable decision.

\subsection{University knowledge community}

Knowledge of spark is generated in the interaction between people. University Knowledge Community should absorb nutrition from the theory of knowledge management and theory of Learning Organization, utilize IT technology to construct convenient, quick exchange of knowledge community. Teachers and students can have a good time in the knowledge community with free surroundings of exchange and discussion, so as to raise the level of knowledge, increase learning capabilities.

\subsection{University knowledge management portal}

University Knowledge Management Portal would concentrate on presentation of business information and knowledge. It provides a unified entrance for users to access knowledge management. Everyone can design personal space. Here, users can share knowledge, learn knowledge, communicate knowledge.

\section{Conclusion}

UKMS is aimed to support decision based on MIS. MIS is always developed for business and has few functions to support knowledge management .So UKMS provides a universal function model for other MIS. We can believe UKMS will be helpful for the application of knowledge management to improve the efficiency of business process of universities.

\section{References}

1. OASIS (2003) Business Process Execution Language (BPEL4WS, version 1.1). http://xml.coverpages.org/BPELv11-May052003Final.pdf

2. E.Newcomer, G. Lomow, Understanding SOA with Web services, Addison-Wesley, (2005) 
3. M. Alavi and D. E. Leidner, Review: Knowledge Management and Knowledge Management Systems: Conceptual Foundations and Research Issues, MIS Quarterly Vol. 25 No. 1(2001) 107-136.

4. W. Staniszkis and E. Staniszkis, Intelligent Agent-Based Expert Interactions in a Knowledge Management Portal , R. Traunmüller (Ed.): EGOV 2003, LNCS 2739(2003) 296-299.

5. H. Benbya, G. Passiante, Nassim Aissa Belbaly,Corporate portal: a tool for knowledge management synchronization, International Journal of Information Management 24 (2004) 201-220.

6. N. Josuttis, SOA in Practice The Art of Distributed System Design , 2007(8) O'Reilly Media ,Inc.

7. L.J. Zhang, J.Zhang and H.Cai , Services Computing, Jointly published with Tsinghua University Press,2007. 